\title{
BIOACTIVITY-GUIDED ISOLATION OF MEMORY-ENHANCING COMPOUND FROM CHLOROFORM EXTRACT OF ROOTS OF PLUMBAGO ZEYLANICA LINN.
}

\author{
VAIBHAV UPLANCHIWAR ${ }^{1}$, GUPTA MK ${ }^{1}$, RUPESH K GAUTAM ${ }^{2 *}$ \\ ${ }^{1}$ Department of Pharmacy, Oriental University, Indore, Madhya Pradesh - 453 555, India. ${ }^{2}$ Department of Pharmacology, MM School of \\ Pharmacy, Maharishi Markandeshwar University, Sadopur, Ambala - 134 007, Haryana, India. Email: drrupeshgautam@gmail.com
}

Received: 30 April 2018, Revised and Accepted: 25 May 2018

\section{ABSTRACT}

Objective: The main aim of our study is to isolate the active compound from roots of Plumbago zeylanica Linn. by bioactivity-guided isolation and evaluate its memory-enhancing effect by Morris water maze.

Methods: Roots were extracted by successive solvent methods by petroleum ether, chloroform, methanol, butanol, and finally, water. Chloroform extract was selected for isolation, and plumbagin was isolated by hexane and ethyl acetate as solvent system. Plumbagin was evaluated by Morris water test, and brain acetylcholine esterase level was measured.

Result: Plumbagin showed a significant decrease of escape latency and increase of time spent in target quadrant by mice in Morris water maze indicating improvement of learning and memory. It also significantly decreases the cholinesterase level in the brain.

Conclusion: Learning and memory of mice doubtless may be through embarrassment of brain acetyl cholinesterase activity and through involvement of GABA-benzodiazepine pathway. Further detailed study is required to explore the other possible mechanisms for the management of cognitive disorders.

Keywords: Bioactivity-guided isolation, Plumbagin, Cholinesterase level, Morris water maze, Locomotor activity.

(c) 2018 The Authors. Published by Innovare Academic Sciences Pvt Ltd. This is an open access article under the CC BY license (http://creativecommons. org/licenses/by/4. 0/) DOI: http://dx.doi.org/10.22159/ajpcr.2018.v11i7.2708

\section{INTRODUCTION}

Alzheimer's disease is a progressive neurodegenerative disorder characterized by the gradual commencement of dementia. It is characterized by gradually progressive refuse in cognitive function, with deficits, especially in memory recovery [1]. A number of cholinesterase inhibitors are in clinical practice for the management of various cognitive disorders [2]. However, they are associated with a number of adverse effects, i.e., anorexia, nausea, vomiting, diarrhea, and insomnia [3]. Hence, there has been intense attention focused on the part of potential phytochemical to modulate neuronal function and protective mechanism against degeneration. As complementary and alternative therapy, herbal medicine or phytotherapy refers to the medical exploitation of plant components for their curative properties. A number of medicinal plants are reported and widely used in Ayurveda and other system of medicine for neurodegenerative disorders. Among all reported medicinal plants, Plumbago zeylanica (chitraka) is wellknown medicinal plant for neurodegenerative disorders.

P. zeylanica is an old-age Rasayana herb in traditional Ayurveda. P. zeylanica Linn. is distributed as a weed throughout the tropical and subtropical countries of the world [4] native to South Asia and cultivated throughout India and Sri Lanka. It belongs to family Plumbaginaceae [57]. The roots of P. zeylanica are also used as expectorant, antirheumatic, anti-scabies, appetite stimulant, anti-diarrheal, antiperiodic, and antimalarial and for the treatment of leprosy [4] The second hand of whole plant, roots, and powder of the roots $[8,9]$ is in fever and malaria, in opposition to diarrhea, dyspepsia, piles, and skin diseases including leprotic lesions, learning, and memory [10-12].

In our previous study, various extracts of roots of $P$. zeylanica were evaluated by Morris water test and their brain acetylcholine esterase level was measured. Among all the extracts, chloroform extract showed potent activity for learning and memory [13]. Phytochemical study of chloroform extract showed the presence of active compound, i.e., plumbagin. Hence, an attempt was made for the bioactivity-guided isolation of active compound from chloroform extract and its evaluation in various models of learning and memory.

\section{METHODS}

\section{Procurement of plant material}

The roots of $P$. zeylanica were purchased from the market. The roots were taxonomically identified and authenticated by senior botanist. A voucher specimen is preserved in the department for the further reference.

\section{Successive solvent extraction method}

The roots $(250 \mathrm{~g})$ were dried in shade and sliced into small pieces and pulverized using a mechanical grinder for the coarse powder. The coarse powder of root was subjected to Soxhlet extraction using petroleum ether to remove all fats. The marc was dried and then extracted by using chloroform, methanol, butanol, and finally with water for $72 \mathrm{~h}$. After exhaustive extraction, the extracts were filtered, concentrated, and dried. All the extracts were screened for the presence of alkaloids, fatty acids, terpenoids, steroids, flavonoids, and glycosides. Since chloroform extract showed potent activity in Morris water test, it is selected for further isolation and characterization of active compounds.

Chromatographic separation and isolation of active compound Completely dried chloroform extract $(25 \mathrm{~g})$ was subjected to chromatographic separation by loading of extract on glass column $(90 \times 3 c)$. For the stationary phase, silica gel was used. Isolation of compound was followed by gradient elution method. In this method, n-hexane containing increasing amounts of ethyl acetate $190: 10,80: 20$, $70: 30,60: 40,50: 50,40: 60$, and 30:70) was used as the solvent system. The column was eluted by $n$-hexane containing increasing amounts of ethyl acetate till $90 \%$ of the process completed. One thirty-five fractions were together and fractions showing similar chromatogram on thinlayer chromatography plate were pooled together and total four (F1F4) fractions were prepared. The percentage yields of fractions were 
determined. Fractions (F2) eluted showing only one spot on TLC (n-hexane:ethyl acetate, 9:1, $\mathrm{R}_{\mathrm{f}}-0.61$ ) were pooled and evaporated to dryness, yielding plumbagin (F2). After isolation of active compound, melting point of plumbagin was recorded by capillary tube method. For the spectral determination of compound, various spectral methods, i.e., ultraviolet and infrared spectra were followed [14].

\section{Experimental animals}

Disease-free Swiss male albino mice (25-35 g) were used for this experiment, and they were purchased from the Committee for the Purpose of Control and Supervision of Experiments on Animals (CPCSEA) approved vendor. Animals were housed separately in polycarbonate cage in groups of 6-8 per cage under proper laboratory conditions with alternating light and dark cycle of $12 \mathrm{~h}$ each. Before the experiment, the protocol was approved by the Institutional Animal Ethics Committee and animal care was in use as per the strategy of CPCSEA, Ministry of Environment and Forests, Government of India.

\section{Morris water maze}

The method and parameters for learning and memory of mice using Morris water maze were followed as reported earlier [15-17].

Animals were divided in eight groups and six animals were placed in each group. Group 1 served as control and Group 2 as standard drug (physostigmine, $0.1 \mathrm{mg} / \mathrm{kg}$ i.p.) treated. Animals of Groups 3 and 4 were treated by plumbagin in a dose of 1.5 and $3 \mathrm{mg} / \mathrm{kg}$, rats of Groups 5 and 6 were treated by scopolamine and diazepam in a dose of 0.4 and $1 \mathrm{mg} / \mathrm{kg}$, and rats of Groups 7 and 8 were treated by plumbagin and combination of scopolamine and diazepam, respectively, were administered for 15 consecutive days. Escape latency (EL) was recorded $120 \mathrm{~min}$ after drug administration from $11^{\text {th }}$ day to $14^{\text {th }}$ day. On the $15^{\text {th }}$ day, time spent in target quadrant (TSTQ) was noted $120 \mathrm{~min}$ following the drug administration. In case of animals administered with physostigmine, EL and TSTQ were noted after 30 min of drug administration.

\section{Measurement of locomotor activity}

All the eight groups were treated by drugs, respectively, which were administered for 15 successive days. Locomotor activity was measured on the $15^{\text {th }}$ day using actophotometer (INCO, Ambala).

\section{Biochemical estimation}

Collection of brain sample

After the $15^{\text {th }}$ day using Morris water maze, the animals were sacrificed on the $16^{\text {th }}$ day by cervical dislocation. Whole brain was carefully removed from the animals. The fresh whole brain was weighed first and then homogenized in 10 volumes of $0.1 \mathrm{M}$ phosphate buffer ( $\mathrm{pH}$ 8) using a glass homogenizer. The homogenate was centrifuged at $3000 \mathrm{rpm}$ for $10 \mathrm{~min}$ at $4^{\circ} \mathrm{C}$ using refrigerated centrifuge (Remi, Mumbai). The resultant cloudy supernatant liquid was used for the estimation of brain acetylcholinesterase activity [18].

\section{Estimation of acetylcholinesterase activity}

$0.4 \mathrm{ml}$ of brain homogenate was placed into a test tube containing $2.6 \mathrm{ml}$ of phosphate buffer. 5, 5-dithiobis-2-nitrobenzoic acid reagent $(0.1 \mathrm{ml})$ was added to the above mixture, and absorbance was noted at $412 \mathrm{~nm}$. Then, $0.02 \mathrm{ml}$ of acetylcholine iodide solution was added and again absorbance was noted 15 min thereafter. Change in absorbance per minute was calculated [18].

\section{Statistical analysis}

Data were analyzed by analysis of variance followed by Tukey's post hoc test in GraphPad prism. p $<0.05$ was considered as statistically significant. All the results are expressed as mean \pm standard error of the mean.

\section{RESULTS}

Effect of plumbagin on EL and time spent in target quadrant TSTQ EL and time spent in target quadrant are associated with learning and memory, and decrease of EL and increase of TSTQ by mice in Morris water maze indicate an improvement of learning and memory. In our study, plumbagin $(1.5$ and $3 \mathrm{mg} / \mathrm{kg})$ and physostigmine $(0.1 \mathrm{mg} / \mathrm{kg}$, i. p.) administered for 15 successive days. After administration, they significantly decreased EL of mice from $11^{\text {th }}$ to $14^{\text {th }}$ day and augmented TSTQ by mice on the $15^{\text {th }}$ day as compared to the control, thus showing learning and memory enhancement effect. Rats treated by plumbagin in a dose of $3 \mathrm{mg} / \mathrm{kg}$ significantly upturned scopolamine- and diazepaminduced amnesia as compared to scopolamine- and diazepam-treated groups (Figs. 1 and 2).

\section{Effect of plumbagin on locomotor activity of mice}

There was a significant change in locomotor activity in mice treated by plumbagin (1.5 and $3 \mathrm{mg} / \mathrm{kg}$ ) and physostigmine as compared to vehicle-treated control (Fig. 3).

Effect of plumbagin on brain acetylcholine esterase activity of mice Animals treated by plumbagin and physostigmine for 15 successive days produced a significant reduction in brain acetylcholinesterase activity as compared to control group. Mice treated by plumbagin in a dose of $3 \mathrm{mg} / \mathrm{kg}$ showed a highly significant decreasing effect on brain acetylcholinesterase activity compared to rats of control group. Results were expressed in Fig. 4.

\section{DISCUSSION}

Herbs have been employed from 1000 of years, in several forms, under the indigenous system of medicine such as Ayurveda, Unani, and Siddha. The unbelievable development in the ground of synthetic drugs during present era is accompanied by numerous unwanted side effects, whereas plants still grasp their own unique position, with lesser

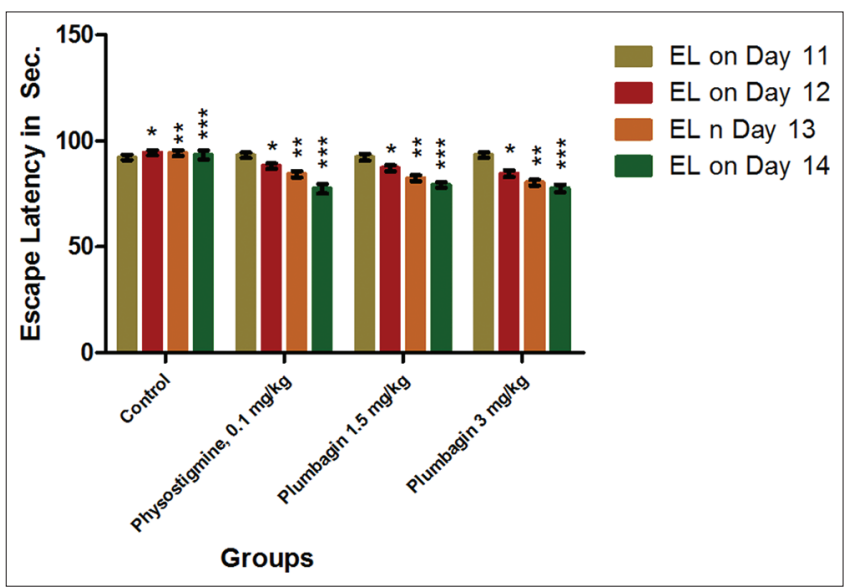

Fig. 1: Effect of plumbagin on escape latency (s) on different days Values are expressed as mean \pm standard error of the mean, $n=6$ in each group; ${ }^{*} \mathrm{p}<0.05$, compared to disease control ${ }^{* *} \mathbf{p}<0.01$, compared to disease control. ${ }^{* * *} \mathbf{p}<0.001$, compared to disease control

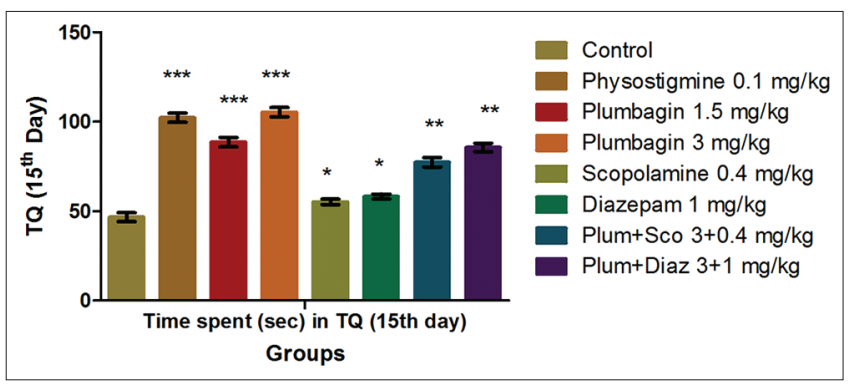

Fig. 2: Effect of plumbagin on $T Q$ on the $15^{\text {th }}$ day. Values are expressed as mean \pm standard error of the mean, $n=6$ in each group; ${ }^{*} \mathbf{p}<0.05$, compared to disease control ${ }^{* *} \mathrm{p}<0.01$, compared to disease control. ${ }^{* * *} \mathrm{p}<0.001$, compared to disease control 


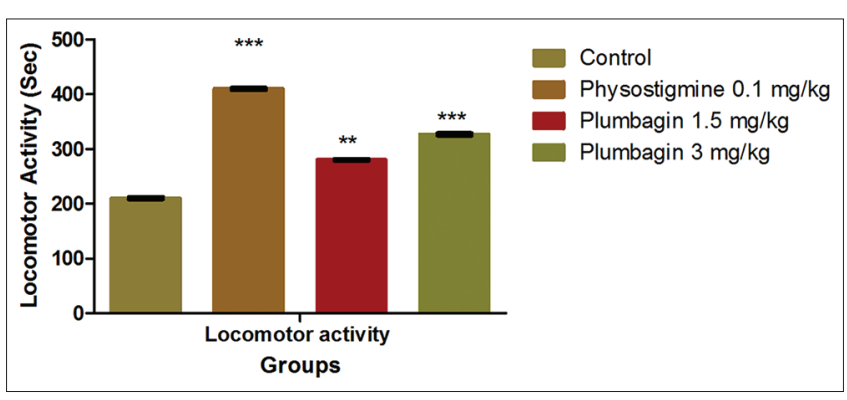

Fig. 3: Effect of plumbagin on locomotor activity in mice. Values are expressed as mean \pm standard error of the mean, $n=6$ in each group; ${ }^{*} \mathbf{p}<0.05$, compared to disease control ${ }^{* *} p<0.01$, compared to disease control. ${ }^{* * *} \mathrm{p}<0.001$, compared to disease control

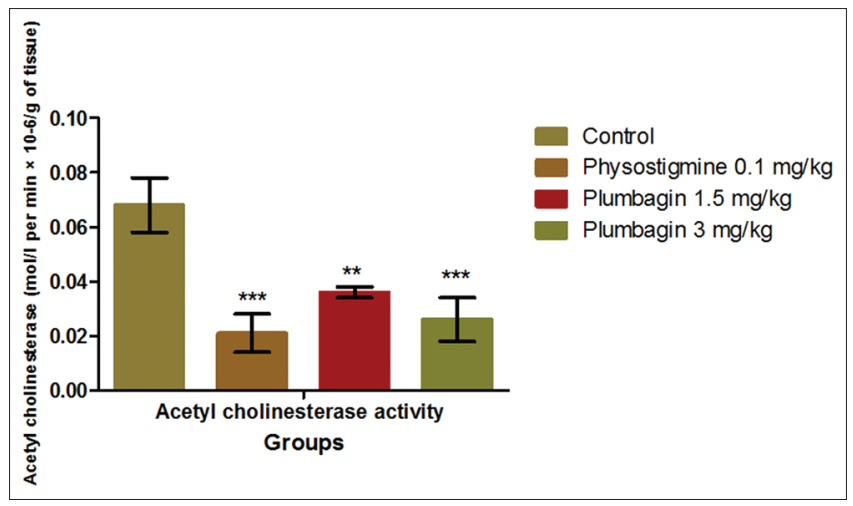

Fig. 4: Effect of plumbagin on acetylcholinesterase level in the brain. Values are expressed as mean \pm standard error of the mean, $\mathrm{n}=6$ in each group; ${ }^{*} \mathrm{p}<0.05$, compared to disease control ${ }^{* *} \mathbf{p}<0.01$, compared to disease control. ${ }^{* * *} \mathbf{p}<0.001$, compared to disease control

side effects and more safety [19-21]. In our present investigation, bioactivity-guided isolation was followed for the isolation of plumbagin and it was administered for 15 successive days. Morris water test was employed as a behavioral model for the evaluation of learning and memory and plumbagin considerably improved learning and memory of mice in relevant test.

In our study, we have selected scopolamine and diazepam since they are reported for the impairment of memory in experimental animals [22]. In our investigation, mice treated by plumbagin ( 1.5 and $3 \mathrm{mg} / \mathrm{kg}$, p.o.) administered for 15 successive days significantly overturned amnesia induced by scopolamine and diazepam in mice. By the creation of benzodiazepine receptors and GABAergic system, benzodiazepines produce amnesia in animals [18]. Benzodiazepine-receptor antagonist, i.e., flumazenil has been reported to invalidate benzodiazepine-induced amnesia [23]. Facilitation of cholinergic transmission and inhibition of GABA-benzodiazepine pathway may be probable mechanism of plumbagin in scopolamine- and diazepam-induced amnesia.

Acetylcholine is considered as the most important neurotransmitter involved in the regulation of cognitive functions [24]. Selective loss of cholinergic neurons or decreased synthesis of acetylcholine was reported to be a characteristic feature of dementia of Alzheimer's disease type [25]. Drugs that decrease cholinergic function such as muscarinic receptor antagonist, scopolamine basis deep memory impairments in animals and humans [26,27]. In the present study, plumbagin (1.5 and $3 \mathrm{mg} / \mathrm{kg}$, p.o.) administered for 15 successive days significantly inverted scopolamine-induced amnesia in mice. Plumbagin $(1.5$ and $3 \mathrm{mg} / \mathrm{kg}$ ) also significantly reduced acetylcholinesterase level in the brain of mice as compared to the control. Since the level of acetylcholinesterase is decreased by plumbagin, it might be suggested that the memory-enhancing consequence of plumbagin due to inhibition of acetylcholinesterase leads to increase in brain acetylcholine levels. Thus, the drugs which improve cholinergic function can be used for the treatment of dementia closely connected to Alzheimer's disease.

\section{CONCLUSION}

By this study, it can be concluded that roots of $P$. zeylanica prove its claim for memory-enhancing effect according to Ayurveda and other system of medicine. Plumbagin was isolated as chief active phytoconstituents by bioactivity-guided isolation and it significantly improved learning and memory of mice doubtless through embarrassment of brain acetylcholinesterase activity and through involvement of GABAbenzodiazepine pathway. Further detailed study is required to explore the other possible mechanisms for the management of cognitive disorders.

\section{CONFLICTS OF INTEREST}

The authors declared that they have no conflicts of interest.

\section{AUTHORS' CONTRIBUTION}

All author contributed uniformly.

\section{EFERENCES}

1. Kalaria RN, Maestre GE, Arizaga R, Friedland RP, Galasko D, World Federation of Neurology Dementia Research Group, et al. Alzheimer's disease and vascular dementia in developing countries: Prevalence, management, and risk factors. Lancet Neurol 2008;7:812-26.

2. Ellis JM. Cholinesterase inhibitors in the treatment of dementia. J Am Osteopath Assoc 2005;1053:145-58.

3. Kavirajan H, Schneider LS. Efficacy and adverse effects of cholinesterase inhibitors and memantine in vascular dementia: A metaanalysis of randomised controlled trials. Lancet Neurol 2007:69:782-92.

4. Singh M, Nagori K, Iyer S, Khare G, Sharwan G, Tripathi DK. Ethanomedicinal, traditional and pharmacological aspects of Plumbago zeylanica Linn. Pharmacol Online 2011;3:684-700.

5. Kritikar KR, Basu BD. Indian Medicinal Plants. Vol. 2. Dehradun: Shiva Publishers; 1993.

6. Choudhary AK, Sushanta KC, Azadkhan AK. Antifertility activity of Plumbago zeylanica Linn. root. Ind J Med Res 1982;76:99-101.

7. Chetty KM, Sivaji K, Sudarsanam G, Sekar PH. Pharmaceutical studies and therapeutic uses of Plumbago zeylanica Linn. root. Ethnobot Leaf 2006; 10:294-304.

8. Ahmad I, Aquil F. In-vitro efficacy of bioactive extracts of 15 medicinal plants against ESbetal-producing multidrug- resistant enteric bacteria. Microbiol Res 2007;162:264-75.

9. Natarajan KS, Narasimhan M, Shanmugasundaram KR. Antioxidant activity of a salt-spice-herbal mixture against free radical induction $\mathrm{J}$ Ethnopharmacol 2006;105:76-83.

10. CSIR. The Wealth of India Vol. 1-12. New Delhi: Council for Scientific and Industrial Research (CSIR).

11. Goyal S, Sheth NR, Srivastava DN. Systemic administration of fractions from Nyctanthes arbor-tristis attenuates chronic inflammatory response in Freund's-complete-adjuvant-induced arthritis in rats. Int J Green Pharm 2014;8:147-52.

12. Choudhary NK, Jha AK, Sharma S, Goyal S, Dwivedi J. Antidiabetic potential of chloroform extract of flowers of Calotropis gigantean: An in-vitro and in-vivo study. Int J Green Pharm 2011;5:296-301.

13. Uplanchiwar V, Gupta MK, Gautam RK. Memory enhancing effect of various polar and non-polar extracts of Plumbago zeylanica Linn. roots. Int J Green Pharm 2018;12:S225-8

14. Nayana SK, Shalini AI, Mamta BS. A new isolation method of plumbagin from Plumbago rosea. Pharm Biol 2005;43:551-3.

15. Domange C, Schroeder H, Violle N, Peiffer J, Canlet C, Paris A, et al. Mining the brain metabolome to understand behavioural disruptions induced in mouse fed Hypochoeris radicata (L.), a neurotoxic plant for horse. Neuro Toxicol 2013;38:74-83.

16. Morris R. Developments of a water-maze procedure for studying spatial learning in the rat. J Neurosci Methods 1984;11:47-60.

17. Parle M, Singh N. Reversal of memory deficits by atorvastatin and simvastatin in rats. Yakugaku Zasshi 2007;127:1125-37.

18. Ellman GL, Courtney KD, Andres V Jr, Feather-Stone RM. A new and rapid colorimetric determination of acetyl cholinesterase activity. 
Biochem Pharmacol 1961;7:88-95

19. Gautam RK, Sharma S, Sharma K. Comparative evaluation of antiarthritic activity of Pongamia pinnata and Punica granatum: An in-vitro study. Int J Pharm Pharm Sci 2013;5:721-4.

20. Gautam RK, Sharma S, Sharma K. Comparative evaluation of antiarthritic activity of Salvadora persica Linn. and Asparagus racemosus Willd: An in-vitro study. Indo Am J Pharm Res 2013;3:8222-7.

21. Gautam R, Sharma SC. Antiulcer activity of Punica granatum Linn. in diabetic rats. Int J Pharm Pharm Sci 2012;4:459-61.

22. Parle M, Dhingra D. Ascorbic acid: A promising memory-enhancer in mice. J Pharmacol Sci 2003;93:129-35.

23. Singh N, SharmaA, Singh M. Possible mechanism of alprazolam-induced amnesia in mice. Pharmacology 1998;56:46-50.

24. Jensen LH, Stephens DN, Sarter M, Petersen EN. Bidirectional effects of beta-carbolines and benzodiazepines on memory processes. Brain Res Bull 1987;19:359-64.

25. Hasselmo ME. The Role of acetylcholine in learning and memory. Curr Opin Neurobiol 2006;16:710-5.

26. Watanabe $T$, Yamagata $N$, Takasaki $K$, Sano $K$, Hayakawa K, Katsurabayashi $\mathrm{S}$, et al. Decreased acetylcholine release is correlated to memory impairment in the $\mathrm{Tg} 2576$ transgenic mouse model of Alzheimer's disease. Brain Res 2009;1249:222-8.

27. Deutsch JA, Rocklin KW. Amnesia induced by scopolamine and its temporal variations. Nature 1967;216:89-90. 